\title{
An evidence-based review of linezolid for the treatment of methicillin-resistant Staphylococcus aureus (MRSA): place in therapy
}

This article was published in the following Dove Press journal:

Core Evidence

10 December 2012

Number of times this article has been viewed

\author{
Richard R Watkins' \\ Tracy L Lemonovich ${ }^{2}$ \\ Thomas M File $\mathrm{Jr}^{3}$ \\ 'Division of Infectious Diseases, \\ Akron General Medical Center, Akron, \\ $\mathrm{OH}$, USA; ${ }^{2}$ Division of Infectious \\ Diseases and HIV Medicine, University \\ Hospitals Case Medical Center, \\ Cleveland, OH, USA; ${ }^{3}$ Division of \\ Infectious Diseases, Summa Health \\ System, Akron, OH, USA
}

\begin{abstract}
Methicillin-resistant Staphylococcus aureus (MRSA), including community-associated and hospital-associated strains, is a major cause of human morbidity and mortality. Treatment options have become limited due to the emergence of MRSA strains with decreased sensitivity to vancomycin, which has long been the first-line therapy for serious infections. This has prompted the search for novel antibiotics that are efficacious against MRSA. Linezolid, an oxazolidinone class of antibiotic, was approved by the Food and Drug Administration in 2000 for treatment of MRSA infections. Since then, there have been a multitude of clinical trials and research studies evaluating the effectiveness of linezolid against serious infections, including pneumonia (both community- and hospital-acquired), skin and soft-tissue infections such as diabetic foot ulcers, endocarditis, osteomyelitis, prosthetic devices, and others. The primary aim of this review is to provide an up-to-date evaluation of the clinical evidence for using linezolid to treat MRSA infections, with a focus on recently published studies, including those on nosocomial pneumonia. Other objectives are to analyze the cost-effectiveness of linezolid compared to other agents, and to review the pharmokinetics and pharmacodynamics of linezolid, emphasizing the most current concepts.
\end{abstract}

Keywords: linezolid, MRSA, clinical trials, pneumonia, skin infections

Core evidence clinical impact summary for linezolid in the treatment of methicillin-resistant Staphylococcus aureus (MRSA)

\begin{tabular}{|c|c|c|}
\hline $\begin{array}{l}\text { Outcome } \\
\text { measure }\end{array}$ & Evidence & Implications \\
\hline $\begin{array}{l}\text { Disease-oriented } \\
\text { evidence }\end{array}$ & $\begin{array}{l}\text { Demonstrates good efficacy for the } \\
\text { treatment of infections caused by } \\
\text { MRSA }\end{array}$ & $\begin{array}{l}\text { May be used as monotherapy in } \\
\text { treating MRSA infections except for } \\
\text { bacteremia and/or endocarditis }\end{array}$ \\
\hline $\begin{array}{l}\text { Patient-oriented } \\
\text { evidence }\end{array}$ & $\begin{array}{l}\text { Multiple randomized clinical trials } \\
\text { show good outcome data }\end{array}$ & $\begin{array}{l}\text { Careful monitoring for potential } \\
\text { adverse events (eg, bone marrow } \\
\text { suppression, serotonin syndrome) is } \\
\text { necessary while on therapy }\end{array}$ \\
\hline Economic evidence & $\begin{array}{l}\text { Costly compared to other drugs; } \\
\text { should not be used as first } \\
\text { line therapy for mild disease in } \\
\text { outpatients }\end{array}$ & $\begin{array}{l}\text { Cost-effective for hospitalized } \\
\text { patients with serious infections } \\
\text { primarily by decreasing length of stay }\end{array}$ \\
\hline
\end{tabular}

\section{Introduction}

Infections from methicillin-resistant Staphylococcus aureus (MRSA) in humans run the gamut in severity from boils to bacteremia and septic shock. The current epidemic of MRSA infections that began in the mid-1990s has led to the increased 
use of vancomycin in hospitalized patients. ${ }^{1}$ Vancomycin, a glycopeptide antibiotic that inhibits cell-wall synthesis, has become the standard therapy to which other antibiotics are compared. Over the last several years, an increase in vancomycin minimum inhibitory concentrations (MICs) has been observed (the so-called MIC creep), as well as pharmacokinetic/pharmacodynamics data suggesting that standard doses do not reach high percent target attainment of MIC of 4., ${ }^{2,3}$ This prompted the Clinical and Laboratory Standards Institute to lower the upper limit of vancomycin susceptibility from $4 \mu \mathrm{g} / \mathrm{mL}$ to $2 \mu \mathrm{g} / \mathrm{mL}$ in $2006 .{ }^{4}$ However, vancomycin treatment failures can occur even when MICs are within the susceptible range. ${ }^{5}$ Furthermore, strains of MRSA with higher vancomycin MICs have been associated with increased mortality. ${ }^{6}$ MRSA strains with decreased susceptibility to vancomycin (mediated by the vanA operon from enterococci), while still rare in the United States, have been reported. ${ }^{7,8}$ Investigators have established the mechanism of resistance to be the development of structural changes in the bacterial cell wall. ${ }^{9}$

These concerns have led to the development of novel antibiotics to treat MRSA. One of these is linezolid (Zyvox - Pfizer), a member of the oxazolidinone family that was approved by the US Food and Drug Administration in April 2000 to treat community-acquired and nosocomial pneumonias and skin and soft-tissue infections (SSTIs) caused by MRSA. ${ }^{10}$ Since its initial approval, significant clinical research data have been published that enhance our understanding of this antibiotic. In this review, we focus on the current evidence for treating MRSA infections with linezolid and discuss its pharmacologic and antimicrobial properties. In particular, recent studies on linezolid for treatment of MRSA pneumonia will be evaluated.

\section{Methods}

A literature search using the PubMed database was conducted using the keywords "linezolid" and "MRSA." Articles were limited to those published in English. A total of 979 articles were retrieved and reviewed, of which 103 were determined to be in the scope of this review. The search included articles that were in the PubMed database as of September 2012.

\section{MRSA infections}

After the introduction of penicillin, penicillinase-producing strains of $S$. aureus were soon isolated. To overcome this clinical setback, researchers developed the semisynthetic antibiotic methicillin, which was resistant to the $\beta$-lactam ring-cleaving mechanism of penicillinase. However, by the early 1960s, methicillin-resistant strains of $S$. aureus had been detected. ${ }^{11}$ Initially confined to hospitalized patients in the United Kingdom, these strains began to spread worldwide in the 1980s. Indeed, methicillin-resistant strains now account for $25 \%-50 \%$ or more of $S$. aureus isolates from hospitals (HA-MRSA) in the United States and several other industrialized countries. ${ }^{12,13}$ Over the last decade, communityassociated MRSA (CA-MRSA) infections have emerged and are now a major public health concern. ${ }^{14}$ In the US, the predominant strain has been the Panton-Valentine leukocidin (PVL)-positive USA 300 clone, while in Europe it is the ST80 clone. ${ }^{15}$ It is predicted that CA-MRSA will eventually become the predominant strain in hospitals, due to its increased virulence, higher fitness, and expanding community reservoir. ${ }^{16}$ However, recent reports have challenged this assumption. One showed the proportion of CA-MRSA SSTIs peaked at $62 \%$ in 2006 before decreasing annually to $52 \%$ in 2010 ( $P<0.001$ for trend $).{ }^{17}$ A population-based surveillance study for MRSA using data from 2005 to 2008 also determined the rates of invasive HA-MRSA infections declined. ${ }^{18}$ These findings suggest that the current MRSA epidemic may have peaked. Nonetheless, these are only two studies, and additional ones, including from outside the US, are needed.

In general, CA-MRSA and HA-MRSA strains are differentiated by the types of infections they produce, with the former most often causing SSTIs (eg, abscesses and cellulitis), while the latter cause more invasive infections (eg, pneumonia, bacteremia, and osteomyelitis). But there is significant overlap in the diseases caused by CA-MRSA and HA-MRSA strains. For instance, one report found the USA300 strain of CA-MRSA responsible for $20 \%$ of nosocomial bacteremias in a Detroit hospital. ${ }^{19}$ The Centers for Disease Control and Prevention has defined an infection caused by CA-MRSA as occurring in an outpatient or within 48 hours of hospitalization and no risk factors for HA-MRSA. ${ }^{20}$ These include hemodialysis, surgery, residency in an extended-care facility, hospitalization within the preceding year, or the presence of an indwelling catheter at the time of culture. ${ }^{20}$ CA-MRSA strains have been associated with outbreaks of SSTIs in a wide range of groups, such as athletes, incarcerated individuals, soldiers, and disadvantaged urban populations. ${ }^{21}$ Moreover, CA-MRSA infections often afflict multiple members of a household, likely the result of asymptomatic nasal carriage. ${ }^{22}$

There are several virulence factors that MRSA uses to overcome the host's immune response. One of the most extensively studied has been PVL, a bicomponent exotoxin 
that forms pores in the membranes of leukocytes, leading to their lysis. Most strains of CA-MRSA carry the PVL genes $l u k S$ and $l u k F$, while HA-MRSA ones usually do not. Early in the MRSA epidemic, researchers believed PVL was the main reason for the high virulence seen with CA-MRSA infections. ${ }^{23}$ However, more recent evidence casts doubt on PVL being a major virulence determinant, as clones that lack PVL genes still show significant virulence. ${ }^{24}$ Production of PVL is increased in vitro by $\beta$-lactam antibiotics through transcriptional activation, while antibiotics that decrease protein synthesis (eg, linezolid) decrease its production. ${ }^{25}$ Additional virulence factors are also believed to contribute to the pathogenesis of CA-MRSA and HA-MRSA infections. These include phenol-soluble modulins, $\alpha$-toxin, arginine catabolic mobile element, superantigens, and biofilms, and have been recently reviewed. ${ }^{26}$

\section{Linezolid: the first oxazolidinone}

The first member of a novel class of antibiotics called oxazolidinones, linezolid has proven to be effective in a wide range of Gram-positive infections. Unlike many other classes of antimicrobials (eg, beta-lactams, aminoglycosides, macrolides), linezolid is a completely synthetic compound (Figure 1). Its mechanism of action is to inhibit bacterial protein synthesis by binding to $23 \mathrm{~S}$ rRNA in the catalytic site of the $50 \mathrm{~S}$ ribosome. ${ }^{27}$ Currently linezolid is FDA-approved to treat the following conditions: (1) vancomycin-resistant Enterococcus faecium infections, including cases with concurrent bacteremia; (2) nosocomial pneumonia caused by S. aureus, including methicillin-susceptible (MSSA) and -resistant strains, or Streptococcus pneumoniae (including multidrugresistant strains); (3) complicated skin and skin-structure infections, including diabetic foot infections (DFIs), without concomitant osteomyelitis, caused by $S$. aureus (MSSA and MRSA), Streptococcus pyogenes, or Streptococcus agalactiae; (4) uncomplicated skin and skin-structure infections caused by

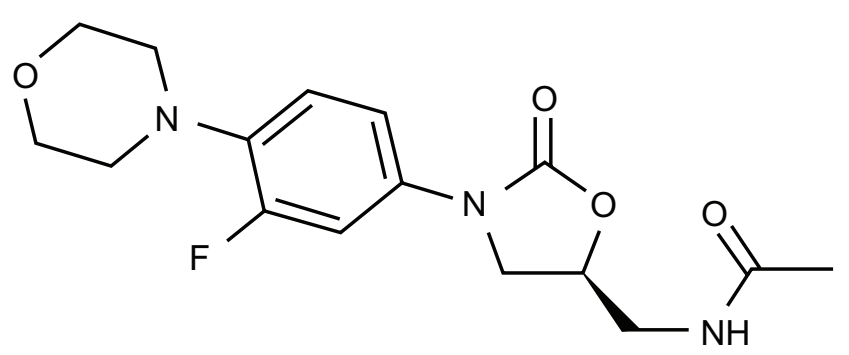

Figure I Chemical structure of linezolid. Its molecular weight is 337.35 and its empirical formula is $\mathrm{C}_{16} \mathrm{H}_{20} \mathrm{FN}_{3} \mathrm{O}_{4}$.

Note: The activity of the drug is enhanced by the morpholino group in the first ring (from the left) and the fluoride atom in the second ring.
MSSA or S. pyogenes; (5) community-acquired pneumonia caused by $S$. pneumoniae, including cases with concurrent bacteremia, or MSSA.

Linezolid has a favorable pharmacokinetic profile that demonstrates active concentrations into a wide range of tissues. ${ }^{28}$ In one study, the mean linezolid concentration in infected soft tissue was $51 \%$ of the corresponding serum concentration. ${ }^{29}$ In another study on patients with diabetic foot ulcers, investigators found that linezolid penetrated well from plasma into both healthy and infected subcutaneous tissue. ${ }^{30}$ The mean protein binding was $15 \%$, was not concentrationdependent, and varied between patients. The metabolism of the drug is not affected by the cytochrome $\mathrm{P} 450$ pathway. It is available in both an intravenous and oral formulation, with the latter having 100\% bioavailability. Sex and age do not have a significant effect on pharmacokinetics of the drug, and no dose modification is needed in mild to moderate liver failure or any degree of renal failure. Linezolid is bacteriostatic and exhibits a significant postantibiotic effect against susceptible bacteria. ${ }^{31}$ Sepsis does not appear to alter the pharmacokinetics of the drug. ${ }^{31}$

The side effects of linezolid are generally mild, especially if given for 28 days or fewer of therapy. The most common ones include diarrhea (4\%), nausea $(3.3 \%)$, and headache $(1.9 \%) .{ }^{10}$ Laboratory abnormalities include anemia and thrombocytopenia, which are reversible. Chronic liver disease seems to increase the risk for linezolid-induced thrombocytopenia. ${ }^{32}$ More serious adverse events occur mostly in those treated longer than 28 days and can include lactic acidosis, irreversible peripheral neuropathy, and optic neuritis. ${ }^{33}$ Linezolid inhibits monoamine oxidase and can induce serotonin toxicity in patients concurrently taking selected serotonin reuptake inhibitors. ${ }^{33}$ Symptoms include confusion, agitation, hypertension, and acute renal failure. ${ }^{34,35}$ Also, concurrent monoamine oxidase inhibitor and linezolid therapy has been associated with hypoglycemia. This was recently reported in a 64-year-old man with type 2 diabetes who was treated with linezolid for cellulitis. ${ }^{36}$ The patient's symptomatic hypoglycemia resolved once the linezolid was discontinued and vancomycin was started.

Like all other antibiotics to date, the emergence of bacterial resistance to linezolid was only a matter of time. Earlier investigators hypothesized that naturally occurring resistance mechanisms would be slow to develop because of linezolid's synthetic composition. ${ }^{10}$ However, resistant strains of $S$. aureus soon developed through mutations within the domain $\mathrm{V}$ region of the $23 \mathrm{~S}$ ribosomal RNA (rRNA) gene. ${ }^{37}$ The $c f r$ gene can transfer linezolid resistance and has 
been associated with an outbreak of MRSA infections in an intensive care unit. ${ }^{38}$ Fortunately, a recent study found the rate of linezolid resistance among MRSA strains in the US remains low $(<1 \%)$ and has been stable since surveillance began in $2006 .{ }^{39}$

\section{Evidence from clinical trials}

\section{Pneumonia}

There have been several studies that investigated linezolid for treating pneumonia caused by MRSA (Table 1). The majority have evaluated it for nosocomial infections. Many of these compared clinical outcomes between linezolid and other antibiotics, particularly vancomycin, since it has long been regarded as the gold standard for treating MRSA pneumonia. One meta-analysis of nine randomized trials that compared linezolid with vancomycin (in seven trials) or teicoplanin (in two trials) for nosocomial pneumonia found similar rates of clinical cure and microbiologic eradication. ${ }^{40}$ Furthermore, no differences in clinical cure or microbiologic eradication were observed in a subgroup analysis of patients with MRSA. There was a higher risk of thrombocytopenia (relative risk [RR] 1.93, 95\% confidence interval $[\mathrm{CI}] 1.30-2.87 ; P=0.001$ ) and gastrointestinal events (RR 2.02, 95\% CI 1.10-3.70; $P=0.02$ ) with linezolid, but there was no difference in the risk of renal dysfunction (RR $0.89,95 \%$ CI $0.56-1.43 ; P=0.64$ ) or all-cause mortality (RR $0.95,95 \%$ CI $0.76-1.18 ; P=0.63$ ). Another meta-analysis of eight randomized controlled trials found linezolid was not superior to glycopeptide antibiotics for clinical success, microbiologic success, or mortality. ${ }^{41}$ As in the preceding study, the subgroup analysis of patients with MRSA showed no differences in clinical success compared to patients without MRSA. The risk for adverse events was not different between linezolid and the glycopeptide antibiotics.

A recent prospective, randomized, double-blind multicenter trial compared linezolid to vancomycin for the treatment of hospital-acquired pneumonia (HAP) or healthcare-associated pneumonia (HCAP) due to proven MRSA. ${ }^{42}$ At the end of the study, the success rate was $57.6 \%$ for

Table I Trials of Linezolid for MRSA pneumonia

\begin{tabular}{|c|c|c|c|}
\hline Author, year, reference & Type of study & Level of evidence & Results \\
\hline Wunderink $R$ et $\mathrm{al}^{42} 2012$ & RCT for nosocomial PNA & 2 & $\begin{array}{l}57 \% \text { of patients treated with linezolid vs } 46 \% \text { with } \\
\text { vancomycin achieved clinical success }(P=0.042) \text {; } \\
60 \text {-day mortality was similar. }\end{array}$ \\
\hline Alaniz $C$ et al $\left.\right|^{95} 2012$ & RCT for nosocomial PNA & 2 & $\begin{array}{l}\text { Linezolid showed benefit in clinical response but not } \\
\text { survival vs vancomycin. }\end{array}$ \\
\hline Watanabe $A$ et al ${ }^{96} 2012$ & $\begin{array}{l}\text { Prospective observational } \\
\text { trial on nosocomial PNA }\end{array}$ & 3 & $\begin{array}{l}\text { Of } 13 \text { participants assessed for clinical responses, } \\
7 \text { were rated as cures, } 3 \text { were failures, and three } \\
\text { indeterminate. }\end{array}$ \\
\hline Karvouniaris $\mathrm{M}$ et al ${ }^{97} 201 \mathrm{l}$ & $\begin{array}{l}\text { Systematic review of } \\
\text { nosocomial PNA }\end{array}$ & 1 & $\begin{array}{l}\text { Despite } \mathrm{pK} / \mathrm{pD} \text { superiority, linezolid failed to show } \\
\text { clear advantage vs vancomycin in recent clinical trials. }\end{array}$ \\
\hline Chan JD et $\mathrm{al}^{98} 20 \mathrm{II}$ & Retrospective cohort on VAP & 3 & $\begin{array}{l}\text { No survival benefit but a trend toward higher cure } \\
\text { rate with linezolid vs vancomycin ( } 89 \% \text { vs } 73 \% \text {, } \\
P=0.006 \text { ). }\end{array}$ \\
\hline Walkey $\mathrm{A}$ et al ${ }^{41} 201 \mathrm{I}$ & $\begin{array}{l}\text { Meta-analysis of } \\
\text { nosocomial PNA }\end{array}$ & 1 & $\begin{array}{l}\text { Evaluation of } 8 \text { RCTs found linezolid was not superior } \\
\text { to vancomycin in efficacy. }\end{array}$ \\
\hline Kalil AC et al ${ }^{40} 2010$ & $\begin{array}{l}\text { Meta-analysis of } \\
\text { nosocomial PNA }\end{array}$ & I & $\begin{array}{l}\text { No difference in all-cause mortality between linezolid } \\
\text { and glycopeptides, clinical cure relative risk was I.00. }\end{array}$ \\
\hline Wunderink $R$ et al $^{99} 2008$ & RCT for VAP & 2 & $\begin{array}{l}\text { Microbiological cure rates were not significantly higher } \\
\text { with linezolid vs vancomycin ( } 56 \% \text { vs } 47 \% ; P=0.757) \text {. }\end{array}$ \\
\hline Kohno S et al ${ }^{100} 2007$ & $\begin{array}{l}\text { RCT of patients with } \\
\text { MRSA infections including PNA }\end{array}$ & 2 & $\begin{array}{l}\text { Success rates were } 60 \%(21 / 35) \text { in the linezolid group } \\
\text { and } 47.4 \%(9 / 19) \text { in the vancomycin group }(P=0.37) \text {. }\end{array}$ \\
\hline Kollef MH et al ${ }^{101} 2004$ & $\begin{array}{l}\text { Retrospective analysis of } \\
\text { two randomized, double-blind } \\
\text { studies on MRSA VAP }\end{array}$ & 2 & $\begin{array}{l}\text { Initial linezolid therapy was associated with significantly } \\
\text { better clinical cure and survival rates vs initial } \\
\text { vancomycin. }\end{array}$ \\
\hline Stevens DL et al ${ }^{102} 2002$ & $\begin{array}{l}\text { RCT for MRSA infections } \\
\text { including nosocomial PNA }\end{array}$ & 2 & $\begin{array}{l}\text { Linezolid was clinically and microbiologically as } \\
\text { effective as vancomycin. }\end{array}$ \\
\hline Rubinstein E et al ${ }^{103} 200 \mathrm{I}$ & RCT for nosocomial PNA & 2 & $\begin{array}{l}\text { Linezolid was statistically noninferior to fixed dose } \\
\text { vancomycin. }\end{array}$ \\
\hline
\end{tabular}

Notes: Level of evidence: I, strong evidence from at least one systematic review; 2, evidence from randomized controlled trials; 3 , evidence from well-designed trials without randomization, single group pre-/postintervention, cohort, time series, or matched case control series; 4, evidence from well-designed nonexperimental, observational studies from more than one center or research group; 5, expert opinion, descriptive studies, and reports of expert committees.

Abbreviations: RCT, randomized controlled trial; PK/pD, pharmacokinetic/pharmacodynamics; PNA, pneumonia; VAP, ventilator-associated pneumonia; MRSA, Methicillinresistant Staphylococcus aureus. 
linezolid and $46.6 \%$ for vancomycin $(95 \%$ CI for difference $0.5 \%-21.6 \% ; P=0.042)$. Among patients who had a respiratory specimen available for culture at the end of treatment, 16 of 92 patients (17\%) who received linezolid had cultures that were persistently positive for MRSA compared with 50 of 109 patients $(46 \%)$ who received vancomycin. In this study, vancomycin was dosed at $15 \mathrm{mg} / \mathrm{kg}$ every 12 hours and adjusted to achieve target trough levels. Linezolid was noninferior and statistically superior to vancomycin in endof-treatment clinical outcome, and microbiologic outcome at end of treatment and end of study. All-cause 60-day mortality was similar (linezolid $15.7 \%$, vancomycin $17.0 \%$ ), as well as the rate of adverse events (Table 2). As would be expected, nephrotoxicity was more common with vancomycin (18.2\%) than linezolid (8.4\%). This was an important study, as it was the first randomized controlled trial to compare vancomycin and linezolid that specifically focused on MRSA respiratory infections. The results have been challenged by some experts over issues of optimal vancomycin dosing. ${ }^{43-45}$

Another group of investigators used a neutropenic mouse model to compare vancomycin to linezolid in MRSA pneumonia. ${ }^{46}$ They found that an optimized dose of vancomycin (achieving an area under the curve [0-24]/MIC ratio $>400$ ) was comparable to linezolid in decreasing bacterial lung concentrations. However, linezolid was more effective than vancomycin against the most virulent MRSA strain (MR33). Whether similar results will be obtained in neutropenic human subjects remains to be elucidated. IMPACT-HAP was a retrospective, observational study of patients with ventilator-associated pneumonia (VAP) due to MRSA treated with linezolid or vancomycin. ${ }^{47}$ Patients were enrolled from five centers in the US. Clinical success was defined as improvement or resolution of signs and symptoms

Table 2 Comparison of adverse events observed with linezolid and vancomycin in intent-to-treat population

\begin{tabular}{lll}
\hline Adverse event & $\begin{array}{l}\text { Linezolid } \\
\text { No }(\%) \\
(\mathbf{n}=\mathbf{5 9 7})\end{array}$ & $\begin{array}{l}\text { Vancomycin } \\
\text { No (\%) } \\
(\mathbf{n}=\mathbf{5 8 7})\end{array}$ \\
\hline Anemia & $30(5.2)$ & $42(7.2)$ \\
Cardiac arrest & $\mathrm{II}(\mathrm{I} .8)$ & $\mathrm{I} 3(2.2)$ \\
Pancreatitis & $5(0.8)$ & $\mathrm{I}(0.2)$ \\
Pancytopenia/neutropenia & $4(0.6)$ & $2(0.4)$ \\
Paresthesia & 0 & $\mathrm{I}(0.2)$ \\
Polyneuropathy & 0 & $\mathrm{I}(0.2)$ \\
Renal failure & $22(3.7)$ & $43(7.3)$ \\
Thrombocytopenia & $8(\mathrm{I.3})$ & $\mathrm{I} 3(2.2)$ \\
\hline
\end{tabular}

Note: Reprinted from Wunderink RG, Niederman MS, Kollef MH, et al. Linezolid in Methicillin-Resistant Staphylococcus aureus Nosocomial Pneumonia: A Randomized, Controlled Study: Clin Infect Dis. 2012;54(5):62I-629 by permission of Oxford University Press. ${ }^{42}$ of VAP by day 14. A propensity-adjusted logistic regression model was used to determine if an association exists between linezolid vs vancomycin and clinical success. A total of 143 patients were evaluated, 80 patients treated with linezolid vs 63 patients treated with vancomycin. Patients receiving linezolid achieved a significantly higher rate of clinical success compared to vancomycin (62/80 [77\%] vs 37/63 [59\%]; $P=0.0018$ ). The results of the propensity-adjusted logistic regression model are shown in Figure 2.

\section{Skin and soft-tissue infections}

Although many different bacterial pathogens can cause SSTIs, MRSA has emerged as the most common etiology in the US for patients who present to emergency departments. ${ }^{48}$ The researchers obtained cultures from adult patients with acute, purulent SSTIs. The prevalence of MRSA was 59\% overall and ranged from $15 \%$ to $74 \%$. The efficacy of linezolid compared to vancomycin for patients with complicated SSTIs (infection that involves deeper soft tissues, requires surgical intervention, or presents with a comorbid condition) was studied in an open-label, randomized, controlled trial in which 285 patients in the microbiologically evaluable population had MRSA infections. ${ }^{49}$ Linezolid therapy was found to be well tolerated and equivalent to vancomycin in treating complicated SSTIs. In a subgroup analysis, linezolid was superior to vancomycin in the treatment of SSTIs due to MRSA. A meta-analysis that included three trials for clinical outcomes $(n=174)$ and three for microbiological outcomes ( $n=439$ ) compared linezolid to vancomycin for MRSA SSTIs. ${ }^{50}$ For clinical outcomes, there were nonsignificant trends in favor of linezolid (RR 0.34, 95\% CI 0.04-2.89; $P=0.32$ ). For microbiological outcomes, there was evidence of linezolid outperforming vancomycin (RR 0.55, 95\% CI 0.30-1.01, $P=0.05)$.

In another study, patients with proven MRSA SSTIs were randomized to receive either linezolid $(n=240)$ or vancomycin $(n=221) .{ }^{51}$ The success rate was significantly higher in linezolid-treated patients in the modified intent-totreat population $(P=0.048)$. The microbiologic success rate was higher for linezolid at the end of treatment $(P<0.001)$ and was similar at the end of the study $(P=0.127)$. Patients who received linezolid had a significantly shorter length of stay and duration of intravenous therapy than patients who received vancomycin. Both antibiotics were well tolerated. The same researchers then conducted a retrospective analysis of the safety and efficacy of oral linezolid for MRSA SSTIs compared to intravenous vancomycin. ${ }^{52}$ Patients received treatment for 7-14 days with either oral linezolid 


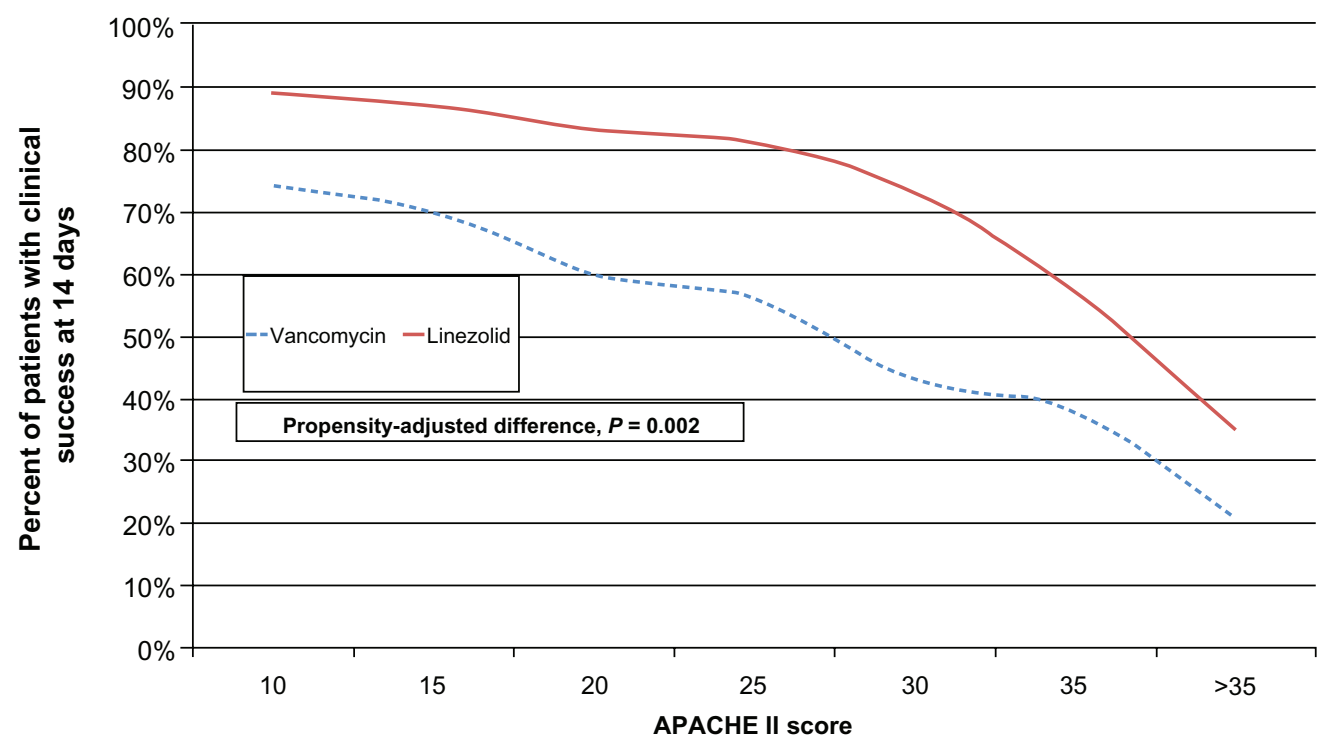

Figure 2 Propensity-adjusted logistic regression model comparing linezolid to vancomycin in patients with ventilator-associated pneumonia from MRSA Note: Data from Peyrani et al. ${ }^{47}$

(600 mg/12 hours; $\mathrm{n}=95)$ or intravenous vancomycin $(15 \mathrm{mg} / \mathrm{kg} / 12$ hours, adjusted for creatinine clearance and trough concentration; $n=210$ ). At the end of the study, the odds ratio for clinical success of oral linezolid therapy vs intravenous vancomycin therapy was 4.0 (95\% CI 1.3-12.0, $P=0.01)$, and the odds ratio for microbiologic success was 2.7 (95\% CI 1.2-5.7, $P=0.01)$. Linezolid and vancomycin were recently compared for MRSA SSTIs in patients with and without peripheral vascular disease. ${ }^{53}$ Among patients with vascular disease (linezolid, $\mathrm{n}=139$; vancomycin, $\mathrm{n}=135$ ), the clinical success rate was $80.4 \%$ and $66.7 \%(P=0.02)$ for patients treated with linezolid and vancomycin, respectively. In those without vascular disease (linezolid, $\mathrm{n}=91$; vancomycin, $\mathrm{n}=112$ ), the clinical success rate was $94.5 \%$ and $89.4 \%$, respectively $(P=0.24)$. Thus, data from these studies underscore the view that linezolid is a safe and effective alternative to vancomycin for treating MRSA SSTIs.

\section{Bone and joint infections}

Osteomyelitis is a challenging condition to treat because of the poor penetration of antibiotics into bone. In clinical practice, antibiotics are often prescribed for prolonged courses, ie, 6-8 weeks or longer. This has limited the role of linezolid, because of its increased risk for bone marrow suppression when prescribed for longer than 4 weeks. To date, no randomized, controlled clinical trial in humans has been conducted on the effectiveness of linezolid in osteomyelitis. Falagas et al in 2007 reviewed the published experience with linezolid for osteomyelitis, which included case reports, analysis of data from the linezolid compassionate-use program, and several small prospective case series. ${ }^{54}$ They reported that successful outcomes or cure occurred in 55\%-100\% of published cases. In a retrospective chart-review study, 66 patients with osteomyelitis treated with linezolid were identified, including 27 with infected prosthetic joints. ${ }^{55}$ The primary pathogen was MRSA (49/72 strains, 68\%), and the median duration of treatment was 13 weeks. At the end of treatment, $56(84.8 \%)$ of the patients were cured, and during the posttreatment follow-up (median duration 15 months, range 12-36 months), four relapses occurred, giving an overall cure rate of $79 \%$. Adverse events were reported in $51.5 \%$ of subjects, and $34.8 \%$ of subjects discontinued treatment because of them. These data on efficacy are comparable to another retrospective study from Taiwan that evaluated linezolid for osteomyelitis. ${ }^{56}$ It included 53 patients, 42 (79.2\%) of whom had MRSA. The median duration of linezolid was 25 days (range 3-301 days). Of the 51 patients eligible for outcome assessment, 41 (80.4\%) had a favorable outcome and ten failed therapy. On univariate analysis, chronic renal or urinary disease, gastrointestinal disease, a higher whiteblood-cell count, a higher alanine aminotransferase level, or a higher creatinine level prior to linezolid treatment was significantly associated with a failed outcome. On multivariate analysis, underlying gastrointestinal disease was significantly associated with a failed outcome $(P=0.008)$. Half of the patients with failed outcomes had retained surgical implants, which is not surprising given that removal of infected material and tissue is paramount in this disease. Thirteen patients developed thrombocytopenia and nine patients developed anemia during linezolid treatment, while 
treatment was stopped in six patients $(11.3 \%$ of 53 cases $)$ due to adverse events.

Recently, researchers used a rat model of osteomyelitis to compare rifampin monotherapy to rifampin plus vancomycin or linezolid in MRSA foreign-body osteomyelitis. ${ }^{57}$ They implanted a titanium wire in the left tibias of the animals after drilling a hole and injecting MRSA into the bone. Treatment was initiated 4 weeks after the procedure, and 61 animals were arbitrarily assigned to one of four treatment arms: rifampin, rifampin plus linezolid, rifampin plus vancomycin, or no treatment. Antibiotics were administered intraperitoneally for 21 days, and then the bone was removed and cultured. Differences in colony counts were significant in all the treatment groups compared to controls $(P<0.0001)$. Evidence of resistance occurred in ten animals in the rifampin group (63\%), two in the linezolid-rifampin group (14\%), and one animal in the vancomycin-rifampin group (8\%). Thus, combination therapy with rifampin and linezolid appears effective, albeit in a rat model of MRSA chronic osteomyelitis, and protects against the development of rifampin resistance. Whether this combination is safe in humans with osteomyelitis is unknown, and alternatives (ie, vancomycin or daptomycin) with rifampin should likely be used as first-line therapy. The combination of linezolid and rifampicin was shown to significantly reduce the incidence of anemia among patients with bone and joint infections compared to linezolid alone, but not have an effect on thrombocytopenia and peripheral neuropathy rates. ${ }^{58}$

\section{Diabetic foot infections}

DFIs are common and associated with significant morbidity, such as amputation. MRSA has become an increasingly recognized pathogen in DFIs. A review of 20 studies conducted between 1993 and 2007 found that the prevalence of MRSA ranged from $5 \%$ to $30 \%{ }^{59}$ Risk factors for MRSA in DFIs include previous long-term or inappropriate use of antibiotics, previous hospitalization, long duration of the foot wound, the presence of osteomyelitis, and nasal carriage of MRSA. ${ }^{60}$ It is therefore important that wound cultures are obtained before antibiotics are started. Indeed, isolation of MRSA is associated with more treatment failures in DFIs than other kinds of bacteria. ${ }^{61}$ In this study, linezolid was not associated with better outcomes compared to other antibiotics (treatment failure 6/19 [31.6\%] vs 18/49 [36.7\%], $P=0.69)$. An earlier randomized, open-label, multicenter study of patients with DFIs compared linezolid to intravenous ampicillinsulbactam and intravenous and oral amoxicillin-clavulanate (ratio of linezolid to comparator drug recipients, $2: 1$ ). ${ }^{62}$
Among 371 patients, the clinical cure rates with linezolid and the comparators were similar ( $81 \%$ vs $71 \%$, respectively), but were significantly higher for linezolid-treated patients with infected foot ulcers ( $81 \%$ vs $68 \%, P=0.018)$ and for patients without osteomyelitis $(87 \%$ vs $72 \%, P=0.003)$. Pharmacokinetic studies of linezolid in DFIs show that adequate drug levels are achieved in inflamed tissues, and these levels are effective for treating MRSA. ${ }^{63,64}$

\section{Bacteremia and endocarditis}

Given its bacteriostatic mechanism of action, linezolid is generally not recommended as first-line therapy in cases of MRSA bacteremia. Nonetheless, it is sometimes used when options are limited, such as salvage therapy when other drugs have failed or for antimicrobial-resistant pathogens. Investigators from South Korea compared a group of patients with persistent MRSA bacteremia who received linezolid $(\mathrm{n}=38)$ to those who received a glycopeptide $(\mathrm{n}=52) .{ }^{65}$ The results were mixed, as the duration of bacteremia was longer in the linezolid group (median 16 days vs 10 days, $P=0.008$ ) but the 30 -day mortality ( $11 \%$ vs $25 \%, P=0.08)$ had a trend toward being lower in the linezolid group that did not reach statistical significance. This study was limited by the small number of patients in the two groups, which hindered the investigators' ability to detect differences between them. Catheter-related bloodstream infections (CRBSIs) are a distinct subset of bacteremias, and controversy exists regarding the optimal antibiotic and duration of therapy. ${ }^{66}$ To further clarify these issues, an open-label, multicenter, randomized, controlled study of linezolid compared to vancomycin for CRBSIs was conducted and included 739 patients, 49 of whom had MRSA. ${ }^{67}$ Linezolid was found to have microbiologic success rates that were noninferior to vancomycin. Mortality rates were $10.4 \%$ in the linezolid group (28 of 269 patients) and $10.1 \%$ in the control group (26 of 257) in the modified intent-to-treat population (ie, all patients with Gram-positive baseline culture). However, these data need to be interpreted with caution. Because of the small sample size, the CIs were wide and the authors did not calculate a $P$-value nor did they evaluate for noninferiority in the subpopulation of MRSA CRBSIs. An unpublished clinical trial (NCT00037050) compared linezolid \pm aztreonam to vancomycin \pm aztreonam in the treatment of CRBSIs. ${ }^{68}$ Patients with Gram-positive infections had no difference in mortality according to their antibiotic treatment, while mortality was higher in patients treated with linezolid who were infected with Gram-negative organisms alone, with both Gram-positive and Gram-negative organisms, or who 
had no infection when they entered the study. This led the FDA to issue an alert advising clinicians that linezolid is not approved for treating CRBSIs or any infection caused by Gram-negative bacteria. ${ }^{69}$

Currently, vancomycin is the antibiotic of choice for MRSA endocarditis, while daptomycin has been approved for right-sided $S$. aureus endocarditis. Treatment with linezolid has produced mixed results, with case reports showing both successes and failures. ${ }^{70-72}$ An experimental rat model of aortic valve endocarditis compared several antibiotics, including linezolid, and found that all the drug-treated groups had significantly reduced bacterial titers in the vegetations. ${ }^{73}$ A review from 2006 identified eight patients in the literature with MRSA endocarditis treated with linezolid, including one with a prosthetic tricuspid valve. ${ }^{74}$ Five of the eight were cured, including the patient with the prosthetic valve. Two patients had adverse events associated with linezolid: one with anemia and thrombocytopenia, and the other had vomiting and alopecia. Since this review was published, there have not been any large, randomized, controlled clinical trials designed specifically to test the effectiveness of linezolid for MRSA endocarditis. As noted in their follow-up letter, Wilcox et al pointed out the difficulty they had in obtaining the 49 patients with MRSA catheter-related bloodstream infections in the trial, presumably a much more common condition than endocarditis. ${ }^{75}$ Thus, it seems prudent in clinical practice to continue to use other drugs before linezolid in most cases of MRSA endocarditis.

\section{Central nervous system infection}

Linezolid achieves excellent penetration of the central nervous system (CNS), with total serum rates of approximately $70 \%{ }^{76}$ Conversely, vancomycin penetrates the CNS poorly. There have been several case reports describing successful treatment of MRSA CNS infections, but so far no randomized clinical trials. ${ }^{77-80}$ Of the ten patients reported to have CA-MRSA CNS infections, all three who received linezolid had complete resolution, while the seven who received vancomycin had severe complications or died $(P<0.05) .{ }^{81}$ In a single-center study from Turkey, 17 cases of postneurosurgical meningitis treated with linezolid were identified, of whom seven had MRSA and one had mixed MRSA, methicillinresistant coagulase-negative Staphylococcus infection. ${ }^{82}$ The cumulative microbiological success rate was $88 \%$ by day 5 , and there was one death.

Additional studies (including randomized controlled trials) are necessary to further delineate the role of linezolid in the treatment of MRSA CNS infections and to compare it against other drugs such as vancomycin and daptomycin.

\section{Guidelines on treating MRSA infections with linezolid}

The Infectious Diseases Society of America (IDSA) published guidelines specifically on the management of infections caused by MRSA in $2011 .^{83}$ Therein, linezolid is recommended as an initial or alternative therapy for the following conditions: pneumonia, SSTIs, osteomyelitis, septic arthritis, meningitis, brain abscess, subdural empyema, spinal epidural abscess, and septic thrombosis of the cavernous or dural venous sinus. The 2005 American Thoracic Society/ IDSA guidelines on HAP, VAP, and HCAP and the IDSA guidelines on MRSA infections recommended either linezolid or vancomycin for pulmonary infections suspected or proven to be caused by MRSA. ${ }^{84,85}$ These note that linezolid might be preferred in patients at risk for or with renal failure in whom vancomycin is often underdosed. Linezolid also may reduce toxin production in pneumonia, although whether this improves clinical outcomes is not yet clear. ${ }^{84}$

The IDSA bacterial meningitis guidelines recommend linezolid as an alternative agent to vancomycin in cases of MRSA infection. ${ }^{86}$ The recently published guidelines on DFIs recommend linezolid as one of the drugs to treat MRSA and also note that it has been shown to be effective in clinical trials including patients with DFIs. ${ }^{87}$ The SSTI guidelines state that linezolid has excellent efficacy in SSTIs in general and against those due to MRSA specifically; however, they suggest reserving it for patients who have severe infections requiring hospitalization or who have not responded to attempts to eradicate the infection. ${ }^{88}$ A summary of guidelinerecommended uses of linezolid is in Table 3.

\section{Pharmacoeconomic considerations of using linezolid}

Linezolid is a costly medication, especially compared to other commonly prescribed antibiotics for MRSA like vancomycin, doxycycline, and trimethoprim/sulfamethoxazole. But soon after it was approved, the potential cost savings of an early switch from intravenous to oral therapy (given its excellent bioavailability) was appreciated..$^{10}$ Follow-up cost-analysis studies have produced conflicting results, with some finding reduced costs with linezolid, while others did not. In one of these, investigators compared patients with MRSA SSTIs treated with linezolid or vancomycin and determined that length of stay and duration of intravenous therapy were shorter in the linezolid group. ${ }^{89}$ The mean \pm standard deviation 
Table 3 Guideline recommended uses for linezolid

\begin{tabular}{|c|c|}
\hline $\begin{array}{l}\text { Guideline and } \\
\text { reference }\end{array}$ & $\begin{array}{l}\text { Key recommendations and level } \\
\text { of evidence }\end{array}$ \\
\hline MRSA infections ${ }^{83}$ & $\begin{array}{l}\text { Linezolid is one of the recommended antibiotics } \\
\text { for complicated SSTIs (2), pneumonia (2), bone } \\
\text { and joint infections (3), CNS infections (3). }\end{array}$ \\
\hline HAP/VAP/HCAP 84 & $\begin{array}{l}\text { Two large multicenter trials of linezolid } \\
\text { demonstrated equivalence to vancomycin in } \\
\text { patients with HAP (2); linezolid may be better } \\
\text { than vancomycin in patients with renal failure } \\
\text { and VAP (2). }\end{array}$ \\
\hline Bacterial meningitis ${ }^{86}$ & Linezolid is an alternative to vancomycin (3). \\
\hline $\begin{array}{l}\text { Diabetic foot } \\
\text { infections }^{87}\end{array}$ & $\begin{array}{l}\text { Linezolid is one of the recommended } \\
\text { antibiotics (2); it is not approved for osteomyelitis. }\end{array}$ \\
\hline $\begin{array}{l}\text { Skin and soft tissue } \\
\text { infections }{ }^{88}\end{array}$ & $\begin{array}{l}\text { Linezolid is an option due to high prevalence of } \\
\text { CA-MRSA for hospitalized patients with severe } \\
\text { infection or whose infection is progressing } \\
\text { despite empirical antibiotics (2). }\end{array}$ \\
\hline
\end{tabular}

Notes: Level of evidence: I, strong evidence from at least one systematic review; 2, evidence from randomized controlled trials; 3, evidence from well-designed trials without randomization, single group pre-/postintervention, cohort, time series, or matched case control series; 4, evidence from well-designed nonexperimental, observational studies from more than one center or research group; 5, expert opinion, descriptive studies, and reports of expert committees.

Abbreviations: HAP, hospital-acquired pneumonia; VAP, ventilator-associated pneumonia; HCAP, healthcare-associated pneumonia; SSTls, skin and soft tissue infections; CNS, central nervous system; CA-MRSA, community-associated methicillin-resistant Staphylococcus aureus.

cost for patients treated with linezolid vs vancomycin was $\$ 4881 \pm \$ 3987$ vs $\$ 6006 \pm \$ 5039$, respectively $(P=0.041)$. Factors associated with increased cost in the study were vancomycin therapy, age, and comorbidities including diabetes mellitus. Moreover, the cost savings were greater in patients with MRSA SSTIs than other organisms. Another study used a decision analytic model based on published clinical trials to evaluate the cost-effectiveness of linezolid, daptomycin, and vancomycin in treating MRSA SSTIs. ${ }^{90}$ Efficacy was defined as a successfully treated patient who did not have any adverse reactions, and the primary outcome was the incremental cost-effectiveness ratio between the antibiotics. The total direct costs of linezolid, daptomycin, and vancomycin were $\$ 18,057, \$ 20,698$, and $\$ 23,671$, respectively, while the cost-effectiveness ratios were $\$ 37,604, \$ 44,086$, and $\$ 52,663$, respectively. Compared directly to daptomycin, linezolid was the dominant strategy when duration of the two therapies was taken into account.

A similar retrospective analysis on data collected between February and June 2007 at a large referral medical center in Alabama led to different findings. ${ }^{91}$ Primary end points were duration of antibiotic therapy, length of hospital stay, total stay in the intensive care unit, total cost of hospitalization, and adverse antibiotic events. Eighty-two patients with MRSA SSTIs were included, of which 26 received daptomycin,
28 received vancomycin, and 28 received linezolid. The mean duration of antibiotic therapy was similar between the three groups. Mean length of hospitalization was shortest in the vancomycin group (12.3 days), then 12.9 days and 15.7 days for daptomycin and linezolid, respectively. Cost of therapy was greatest for patients treated with linezolid (\$6384), less with daptomycin (\$5364), and least with vancomycin (\$4703). Drug acquisition and administrative costs, including drug levels, were $\$ 123.78$ for vancomycin, $\$ 872$ for linezolid, and $\$ 1017$ for daptomycin. Finally, no drug-related adverse events occurred in either the linezolid or daptomycin groups, while one patient who received vancomycin developed red man's syndrome. The discrepant results of these two studies might be due to different methodologies or the fact that when the data were collected (2007), MRSA strains with higher vancomycin MICs were less common.

French investigators reported that in patients hospitalized for SSTIs from MRSA, the average total cost of treatment was $€ 7778$ for linezolid vs $€ 8777$ for vancomycin. ${ }^{92}$ The mean estimated length of hospitalization after two lines of treatment was 10.7 days for linezolid versus 13.3 days for vancomycin. A study from Germany used a decision analytic model to compare costs and outcomes in patients with MRSA nosocomial pneumonia treated with linezolid or vancomycin..$^{93}$ There was greater clinical cure $(+8.7 \%)$ and survival $(+13.2 \%)$ in the linezolid arm compared to the vancomycin arm at an incremental cost of $€ 420$ per treatment episode. Compared to vancomycin, patients with surgical site infections due to MRSA treated with linezolid during hospitalization and postdischarge had lower costs $(\$ 8923$ vs $\$ 12,481) .{ }^{94}$ Linezolid was also noted to be more effective in treating the infection. Thus, additional large studies are warranted to clarify whether linezolid is more or less cost-effective than other agents, especially in other common infections like DFIs.

\section{Conclusion}

Current treatment options for MRSA infections are limited. Linezolid has proven to be a valuable addition to the antibiotic armamentarium against this common and dangerous pathogen. This is evident by the inclusion of linezolid in multiple clinical practice guidelines. Results from recent clinical trials on linezolid for MRSA pneumonia are valuable for clinicians and provide reassurance that the drug is effective. Controversy exists on whether linezolid is equivalent or actually superior to vancomycin, especially in pneumonia. Experts continue to debate over optimal vancomycin-dosing strategies and how these may alter the 
results of head-to-head trials. Although most patients tolerate linezolid well, clinicians must be cognizant of potential adverse reactions, some of which are serious (anemia, thrombocytopenia) and can be permanent (eg, peripheral neuropathy, optic neuritis). While linezolid-resistant strains of MRSA remain rare, ongoing surveillance is important to optimize infection-control measures to prevent their spread. Additional clinical studies are needed to define better the role of linezolid in treating certain conditions (eg, sepsis, endocarditis) and in different patient populations (eg, HIV/ AIDS), as well as further research on the cost-effectiveness of linezolid and outcome measurements. Cost containment issues also impact antibiotic stewardship policies and healthcare settings with limited resources.

\section{Disclosure}

Dr File Jr has served as a consultant and has received research grants from Pfizer. The authors report no conflicts of interest in this work.

\section{References}

1. Pakyz AL, MacDougall C, Oinonen M, Polk RE. Trends in antibacterial use in US academic health centers: 2002 to 2006. Arch Intern Med. 2008; 168(20):2254-2260.

2. Steinkraus G, White R, Friedrich L. Vancomycin MIC creep in non-vancomycin-intermediate Staphylococcus aureus (VISA), vancomycin-susceptible clinical methicillin-resistant $S$. aureus (MRSA) blood isolates from 2001-05. J Antimicrob Chemother. 2007;60(4):788-794.

3. Wang G, Hindler JF, Ward KW, Bruckner DA. Increased vancomycin MICs for Staphylococcus aureus clinical isolates from a university hospital during a 5-year period. J Clin Microbiol. 2006;44(11):3883-3886.

4. Clinical and Laboratory Standards Institute. Performance Standards for Antimicrobial Susceptibility Testing. CLSI Approved Standard M100-S16. Wayne, PA: The Institute; 2006.

5. Lodise TP, Graves J, Evans A, et al. Relationship between vancomycin MIC and failure among patients with methicillin-resistant Staphylococcus aureus bacteremia treated with vancomycin. Antimicrob Agents Chemother. 2008;52(9):3315-3320.

6. Hidayat LK, Hsu DI, Quist R, Shriner KA, Wong-Beringer A. High-dose vancomycin therapy for methicillin-resistant Staphylococcus aureus infections: efficacy and toxicity. Arch Intern Med. 2006; 166(19):2138-2144.

7. Sievert DM, Rudrik JT, Patel JB, McDonald LC, Wilkins MJ, Hageman JC. Vancomycin-resistant Staphylococcus aureus in the United States, 2002-2006. Clin Infect Dis. 2008;46(5):668-674.

8. Tenover FC, Weigel LM, Appelbaum PC, et al. Vancomycin-resistant Staphylococcus aureus isolate from a patient in Pennsylvania. Antimicrob Agents Chemother. 2004;48(1):275-280.

9. Hiramatsu K. Vancomycin-resistant Staphylococcus aureus: a new model of antibiotic resistance. Lancet Infect Dis. 2001;1(3):147-155.

10. Moellering RC Jr. Linezolid: the first oxazolidinone antimicrobial. Ann Intern Med. 2003;138(2):135-142.

11. Jevons MP, Coe AW, Parker MT. Methicillin resistance in staphylococci. Lancet. 1963;1(7287):904-907.

12. Drago L, De Vecchi E, Nicola L, Gismondo MR. In vitro evaluation of antibiotics' combinations for empirical therapy of suspected methicillin resistant Staphylococcus aureus severe respiratory infections. BMC Infect Dis. 2007;7:111.
13. Dulon M, Haamann F, Peters C, Schablon A, Nienhaus A. MRSA prevalence in European healthcare settings: a review. BMC Infect Dis. 2011;11:138.

14. David MZ, Medvedev S, Hohmann SF, Ewigman B, Daum RS. Increasing burden of methicillin-resistant Staphylococcus aureus hospitalizations at US academic medical centers, 2003-2008. Infect Control Hosp Epidemiol. 2012;33(8):782-789.

15. Otter JA, French GL. Molecular epidemiology of community-associated meticillin-resistant Staphylococcus aureus in Europe. Lancet Infect Dis. 2010;10(4):227-239.

16. D'Agata EM, Webb GF, Horn MA, Moellering RC Jr, Ruan S. Modeling the invasion of community-acquired methicillin-resistant Staphylococcus aureus into hospitals. Clin Infect Dis. 2009;48(3):274-284.

17. Landrum ML, Neumann C, Cook C, et al. Epidemiology of Staphylococcus aureus blood and skin and soft tissue infections in the US military health system, 2005-2010. JAMA. 2012;308(1):50-59.

18. Kallen AJ, Mu Y, Bulens S, et al. Health care-associated invasive MRSA infections, 2005-2008. JAMA. 2010;304(6):641-648.

19. Chua T, Moore CL, Perri MB, et al. Molecular epidemiology of methicillin-resistant Staphylococcus aureus bloodstream isolates in urban Detroit. J Clin Microbiol. 2008;46(7):2345-2352.

20. Morrison MA, Hageman JC, Klevens RM. Case definition for community-associated methicillin-resistant Staphylococcus aureus. J Hosp Infect. 2006;62(2):241.

21. David MZ, Daum RS. Community-associated methicillin-resistant Staphylococcus aureus: epidemiology and clinical consequences of an emerging epidemic. Clin Microbiol Rev. 2010;23(3):616-687.

22. Rafee Y, Abdel-Haq N, Asmar B, et al. Increased prevalence of methicillin-resistant Staphylococcus aureus nasal colonization in household contacts of children with community acquired disease. BMC Infect Dis. 2012;12:45.

23. Vandenesch F, Naimi T, Enright MC, et al. Community-acquired methicillin-resistant Staphylococcus aureus carrying Panton-Valentine leukocidin genes: worldwide emergence. Emerg Infect Dis. 2003;9(8):978-984.

24. Otto M. Basis of virulence in community-associated methicillin-resistant Staphylococcus aureus. Annu Rev Microbiol. 2010;64:143-162.

25. Bernardo K, Pakulat N, Fleer S, et al. Subinhibitory concentrations of linezolid reduce Staphylococcus aureus virulence factor expression. Antimicrob Agents Chemother. 2004;48(2):546-555.

26. Watkins RR, David MZ, Salata RA. Current concepts on the virulence mechanisms of meticillin-resistant Staphylococcus aureus. J Med Microbiol. 2012;61(Pt 9):1179-1193.

27. Leach KL, Brickner SJ, Noe MC, Miller PF. Linezolid, the first oxazolidinone antibacterial agent. Ann N Y Acad Sci. 2011;1222:49-54.

28. Stevens DL, Dotter B, Madaras-Kelly K. A review of linezolid: the first oxazolidinone antibiotic. Expert Rev Anti Infect Ther. 2004;2(1): $51-59$.

29. Stein GE, Schooley S, Peloquin CA, Missavage A, Havlichek DH. Linezolid tissue penetration and serum activity against strains of methicillin-resistant Staphylococcus aureus with reduced vancomycin susceptibility in diabetic patients with foot infections. J Antimicrob Chemother. 2007;60(4):819-823.

30. Wiskirchen DE, Shepard A, Kuti JL, Nicolau DP. Determination of tissue penetration and pharmacokinetics of linezolid in patients with diabetic foot infections using in vivo microdialysis. Antimicrob Agents Chemother. 2011;55(7):3220-3225.

31. MacGowan AP. Pharmacokinetic and pharmacodynamics profile of linezolid in healthy volunteers and patients with Gram-positive infections. J Antimicrob Chemother. 2003;51(Suppl 2):17-25.

32. Ikuta $\mathrm{S}$, Tanimura $\mathrm{K}$, Yasui $\mathrm{C}$, et al. Chronic liver disease increases the risk of linezolid-related thrombocytopenia in methicillin-resistant Staphylococcus aureus-infected patients after digestive surgery. J Infect Chemother:2011;17(3):388-391.

33. Narita M, Tsuji BT, Yu VL. Linezolid-associated peripheral and optic neuropathy, lactic acidosis, and serotonin syndrome. Pharmacotherapy. 2007;27(8):1189-1197. 
34. Go AC, Golightly LK, Barber GR, Barron MA. Linezolid interaction with serotonin reuptake inhibitors: report of two cases and incidence assessment. Drug Metabol Drug Interact. 2010;25(1-4):41-47.

35. McClean M, Walsh JC, Condon F. Serotonin syndrome in an orthopaedic patient secondary to linezolid for MRSA infection. Ir J Med Sci. 2011;180(1):285-286.

36. Bodnar T, Starr K, Halter JB. Linezolid-associated hypoglycemia in a 64-year-old man with type 2 diabetes. Am J Geriatr Pharmacother. 2011;9(1):88-92.

37. Pillai SK, Sakoulas G, Wennersten C, et al. Linezolid resistance in Staphylococcus aureus: characterization and stability of resistant phenotype. J Infect Dis. 2002;186(11):1603-1607.

38. Sánchez García M, De la Torre MA, Morales G, et al. Clinical outbreak of linezolid-resistant Staphylococcus aureus in an intensive care unit. JAMA. 2010;303(22):2260-2264.

39. Flamm RK, Farrell DJ, Mendes RE, et al. LEADER surveillance program results for 2010: an activity and spectrum analysis of linezolid using 6801 clinical isolates from the United States (61 medical centers). Diagn Microbiol Infect Dis. 2012;74(1):54-61.

40. Kalil AC, Murthy MH, Hermsen ED, et al. Linezolid versus vancomycin or teicoplanin for nosocomial pneumonia: a systemic review and metaanalysis. Crit Care Med. 2010;38(9):1802-1808.

41. Walkey AJ, O’Donnell MR, Soylemez Wiener R. Linezolid vs glycopeptide antibiotics for the treatment of suspected methicillinresistant Staphylococcus aureus nosocomial pneumonia. Chest. 2011;139(5):1148-1155.

42. Wunderink RG, Niederman MS, Kollef MH, et al. Linezolid in methicillin-resistant Staphylococcus aureus nosocomial pneumonia: a randomized, controlled study. Clin Infect Dis. 2012;54(5): 621-629.

43. Wolff M, Mourvillier B. Linezolid for the treatment of nosocomial pneumonia due to methicillin-resistant Staphylococcus aureus. Clin Infect Dis. 2012;55(1):160-161.

44. Masuta K, Oba Y, Iwata K. Linezolid versus vancomycin for methicillinresistant Staphylococcus aureus nosocomial pneumonia: controversy continues. Clin Infect Dis. 2012;55(1):161.

45. Taccone FS, Vincent JL, Denis O, Jacobs F. Should we abandon vancomycin for treatment of methicillin-resistant Staphylococcus aureus pneumonia? Still questions to answer. Clin Infect Dis. 2012;55(1): 161-163.

46. Docobo-Pérez F, López-Rojas R, Domínguez-Herrera J, et al. Efficacy of linezolid versus a pharmacodynamically optimized vancomycin therapy in an experimental pneumonia model caused by methicillin-resistant Staphylococcus aureus. J Antimicrob Chemother. 2012;67(8):1961-1967.

47. Peyrani P, Wiemken TL, Zervos MJ, et al. Higher clinical success in patients with ventilator-associated pneumonia due to MRSA treated with linezolid compared to vancomycin: results from the IMPACT-HAP study. Presented at the Infectious Diseases Society of America Annual Meeting; October 17-21, 2012; San Diego, CA, USA.

48. Moran GJ, Krishnadasan A, Gorwitz RJ, et al. Methicillin-resistant $S$. aureus infections among patients in the emergency department. N Engl J Med. 2006;355(7):666-674.

49. Weigelt J, Itani K, Stevens D, et al. Linezolid versus vancomycin in treatment of complicated skin and soft tissue infections. Antimicrob Agents Chemother. 2005;49(6):2260-2266.

50. Dodds TJ, Hawke CI. Linezolid versus vancomycin for MRSA skin and soft tissue infections (systematic review and meta-analysis). ANZ J Surg. 2009;79(9):629-635.

51. Itani KM, Dryden MS, Bhattacharyya H, et al. Efficacy and safety of linezolid versus vancomycin for the treatment of complicated skin and soft-tissue infections proven to be caused by methicillin-resistant Staphylococcus aureus. Am J Surg. 2010;199(6):804-816.

52. Itani KM, Biswas P, Reisman A, Bhattacharyya H, Baruch AM. Clinical efficacy of oral linezolid compared with intravenous vancomycin for the treatment of methicillin-resistant Staphylococcus aureus-complicated skin and soft tissue infections: a retrospective, propensity scorematched, case-control analysis. Clin Ther. 2012; 34(8):1667-1673.
53. Duane TM, Weigelt JA, Puzniak LA, Huang DB. Linezolid and vancomycin in treatment of lower-extremity complicated skin and skin structure infections caused by methicillin-resistant Staphylococcus aureus in patients with and without vascular disease. Surg Infect (Larchmt). 2012;13(3):147-153.

54. Falagas ME, Siempos II, Papagelopoulos PJ, Vardakas KZ. Linezolid for the treatment of adults with bone and joint infections. Int J Antimicrob Agents. 2007;29(3):233-239.

55. Senneville E, Legout L, Valette M, et al. Effectiveness and tolerability of prolonged linezolid treatment for chronic osteomyelitis: a retrospective study. Clin Ther. 2006;28(8):1155-1163.

56. Lu PL, Wang JT, Chen CJ, et al. Compassionate use of linezolid for adult Taiwanese patients with bone and joint infections. Chemotherapy. 2010;56(6):429-435.

57. Vergidis P, Rouse MS, Euba G, et al. Treatment with linezolid or vancomycin in combination with rifampin is effective in an animal model of methicillin-resistant Staphylococcus aureus foreign body osteomyelitis. Antimicrob Agents Chemother. 2011;55(3):1182-1186.

58. Legout L, Valette M, Dezeque H, et al. Tolerability of prolonged linezolid therapy in bone and joint infection: protective effect of rifampicin on the occurrence of anaemia. J Antimicrob Chemother. 2010;65(10):2224-2230.

59. Eleftheriadou I, Tentolouris N, Argiana V, Jude E, Boulton AJ. Methicillin-resistant Staphylococcus aureus in diabetic foot infections. Drugs. 2010;70(14):1785-1797.

60. Liu C, Bayer A, Cosgrove SE, et al. Clinical practice guidelines by the Infectious Diseases Society of America for the treatment of methicillinresistant Staphylococcus aureus infections in adults and children. Clin Infect Dis. 2011;52(3):e18-e55.

61. Vardakas KZ, Horianopoulou M, Falagas ME. Factors associated with treatment failure in patients with diabetic foot infections: an analysis of data from randomized controlled trials. Diabetes Res Clin Pract. 2008;80(3):344-351.

62. Lipsky BA, Itani K, Norden C; Linezolid Diabetic Foot Infections Study Group. Treating foot infections in diabetic patients: a randomized, multicenter, open-label trial of linezolid versus ampicillin-sulbactam/ amoxicillin-clavulanate. Clin Infect Dis. 2004;38(1):17-24.

63. Traunmüller F, Schintler MV, Spendel S, et al. Linezolid concentrations in infected soft tissue and bone following repetitive doses in diabetic patients with bacterial foot infections. Int J Antimicrob Agents. 2010;36(1):84-86.

64. Majcher-Peszynska J, Haase G, Sass M, et al. Pharmacokinetics and penetration of linezolid into inflamed soft tissue in diabetic foot infections. Eur J Clin Pharmacol. 2008;64(11):1093-1100.

65. Park HJ, Kim SH, Kim MJ, et al. Efficacy of linezolid-based salvage therapy compared with glycopeptide-based therapy in patients with persistent methicillin-resistant Staphylococcus aureus bacteremia. J Infect. Epub August 14, 2012.

66. Cosgrove SE, Fowler VG Jr. Optimizing therapy for methicillinresistant Staphylococcus aureus bacteremia. Semin Respir Crit Care Med. 2007;28(6):624-631.

67. Wilcox MH, Tack KJ, Bouza E, et al. Complicated skin and skin-structure infections and catheter-related bloodstream infections: noninferiority of linezolid in a phase 3 study. Clin Infect Dis. 2009;48(2):203-212.

68. ClinicalTrials.gov. Antibiotic treatment for infections of short term in-dwelling vascular catheters due to Gram positive bacteria. Available from: http://clinicaltrials.gov/ct2/show/NCT00037050. Accessed November 5, 2012.

69. Food and Drug Administration. Information for healthcare professionals: linezolid (marketed as Zyvox). 2007. Available from: http://www. fda.gov/Drugs/DrugSafety/PostmarketDrugSafetyInformationfor PatientsandProviders/DrugSafetyInformationforHeathcareProfession als/ucm085249.htm. Accessed October 26, 2012.

70. Corne P, Marchandin H, Macia JC, Jonquet O. Treatment failure of methicillin-resistant Staphylococcus aureus endocarditis with linezolid. Scand J Infect Dis. 2005;37(11-12):946-949. 
71. Nathani N, Iles P, Elliott TS. Successful treatment of MRSA native valve endocarditis with oral linezolid therapy: a case report. $J$ Infect. 2005;51(4):e213-e215.

72. Souli M, Pontikis K, Chryssouli Z, Galani I, Giamarellou H. Successful treatment of right-sided prosthetic valve endocarditis due to methicillinresistant teicoplanin-heteroresistant Staphylococcus aureus with linezolid. Eur J Clin Microbiol Infect Dis. 2005;24(11):760-762.

73. Sacar M, Sacar S, Cevahir N, et al. Comparison of antimicrobial agents as therapy for experimental endocarditis. Tex Heart Inst J. 2010;37(4):400-404.

74. Falagas ME, Manta KG, Ntziora F, Vardakas KZ. Linezolid for the treatment of patients with endocarditis: a systematic review of the published evidence. J Antimicrob Chemother. 2006;58(2):273-280.

75. Wilcox MH, Kunkel MJ, Knirsch C. Reply to Drekonja and Lustberg et al. Clin Infect Dis. 2009;49(2):314-315.

76. Kessler AT, Kourtis AP. Treatment of meningitis caused by methicillin-resistant Staphylococcus aureus with linezolid. Infection. 2007;35(4):271-274.

77. Pistella E, Campanile F, Bongiorno D, et al. Successful treatment of disseminated cerebritis complicating methicillin-resistant Staphylococcus aureus Endocarditis unresponsive to vancomycin therapy with linezolid. Scand J Infect Dis. 2004;36(3):222-225.

78. Fernández-Ruiz M, Cervera C, Pitart C, et al. Community-acquired methicillin-resistant Staphylococcus aureus meningitis complicated by cerebral infarction. Role of antibiotic combination of linezolid plus levofloxacin. Intern Med. 2010;49(18):1971-1974.

79. Al Kandari M, Jamal W, Udo EE, et al. A case of community-onset meningitis caused by hospital methicillin-resistant Staphylococcus aureus successfully treated with linezolid and rifampicin. Med Princ Pract. 2010;19(3):235-239.

80. Saito N, Aoki K, Sakurai T, et al. Linezolid treatment for intracranial abscesses caused by methicillin-resistant Staphylococcus aureus - two case reports. Neurol Med Chir (Tokyo). 2010;50(6):515-517.

81. Naesens R, Ronsyn M, Druwé P, et al. Central nervous system invasion by community-acquired meticillin-resistant Staphylococcus aureus. J Med Microbiol. 2009;58(Pt 9):1247-1251.

82. Sipahi OR, Bardak S, Turhan T, et al. Linezolid in the treatment of methicillin-resistant staphylococcal post-neurosurgical meningitis: a series of 17 cases. Scand J Infect Dis. 2011;43(10):757-764.

83. Liu C, Bayer A, Cosgrove SE, et al. Clinical practice guidelines by the Infectious Diseases Society of America for the treatment of methicillinresistant Staphylococcus aureus infections in adults and children: executive summary. Clin Infect Dis. 2011;52(3):285-292.

84. American Thoracic Society, Infectious Diseases Society of America. Guidelines for the management of adults with hospital-acquired, ventilator-associated, and healthcare-associated pneumonia. Am J Respir Crit Care Med. 2005;171(4):388-416.

85. Stevens DL, Ma Y, Salmi DB, et al. Impact of antibiotics on expression of virulence-associated exotoxin genes in methicillinsensitive and methicillin-resistant Staphylococcus aureus. J Infect Dis. 2007;195(2):202-211.

86. Tunkel AR, Hartman BJ, Kaplan SL, et al. Practice guidelines for the management of bacterial meningitis. Clin Infect Dis. 2004;39(9): $1267-1284$.

87. Lipsky BA, Berendt AR, Cornia PB, et al. 2012 Infectious Diseases Society of America clinical practice guideline for the diagnosis and treatment of diabetic foot infections. Clin Infect Dis. 2012;54(12):e132-e173.

88. Stevens DL, Bisno AL, Chambers HF, et al. Practice guidelines for the diagnosis and management of skin and soft-tissue infections. Clin Infect Dis. 2005;41(10):1373-1406.
89. McKinnon PS, Sorensen SV, Liu LZ, Itani KM. Impact of linezolid on economic outcomes and determinants of cost in a clinical trial evaluating patients with MRSA complicated skin and soft-tissue infections. Ann Pharmacother. 2006;40(6):1017-1023.

90. Bounthavong M, Zargarzadeh A, Hsu DI, Vanness DJ. Costeffectiveness analysis of linezolid, daptomycin, and vancomycin in methicillin-resistant Staphylococcus aureus: complicated skin and skin structure infection using Bayesian methods for evidence synthesis. Value Health. 2011;14(5):631-639.

91. Wright BM, Eiland EH 3rd. Retrospective analysis of clinical and cost outcomes associated with methicillin-resistant Staphylococcus aureus complicated skin and skin structure infections treated with daptomycin, vancomycin, or linezolid. J Pathog. 2011;2011:347969.

92. De Cock E, Sorensen S, Levrat F, et al. Cost-effectiveness of linezolid versus vancomycin for hospitalized patients with complicated skin and soft-tissue infections in France. Med Mal Infect. 2009;39(5):330-340.

93. De Cock E, Krueger WA, Sorensen S, et al. Cost-effectiveness of linezolid vs vancomycin in suspected methicillin-resistant Staphylococcus aureus nosocomial pneumonia in Germany. Infection. 2009;37(2):123-132.

94. Patanwala AE, Erstad BL, Nix DE. Cost-effectiveness of linezolid and vancomycin in the treatment of surgical site infections. Curr Med Res Opin. 2007;23(1):185-193.

95. Alaniz C, Pogue JM. Vancomycin versus linezolid in the treatment of methicillin-resistant Staphylococcus aureus nosocomial pneumonia: implications of the ZEPHyR trial (October). Ann Pharmacother. 2012;46(10):1432-1435.

96. Watanabe A, Goto H, Soma K, et al. Usefulness of linezolid in the treatment of hospital-acquired pneumonia caused by MRSA: a prospective observational study. J Infect Chemother. 2012;18(2):160-168.

97. Karvouniaris M, Makris D, Karabekos D, Zakynthinos E. Nosocomial MRSA pneumonia: data from recent clinical trials. Rev Recent Clin Trials. 2011;6(3):235-240.

98. Chan JD, Pham TN, Wong J, et al. Clinical outcomes of linezolid vs vancomycin in methicillin-resistant Staphylococcus aureus ventilatorassociated pneumonia: retrospective analysis. J Intensive Care Med. 2011;26(6):385-391.

99. Wunderink RG, Mendelson MH, Somero MS, et al. Early microbiological response to linezolid vs vancomycin in ventilator-associated pneumonia due to methicillin-resistant Staphylococcus aureus. Chest. 2008;134(6):1200-1207.

100. Kohno S, Yamaguchi K, Aikawa N, et al. Linezolid versus vancomycin for the treatment of infections caused by methicillinresistant Staphylococcus aureus in Japan. J Antimicrob Chemother. 2007;60(6): 1361-1369.

101. Kollef MH, Rello J, Cammarata SK, et al. Clinical cure and survival in Gram-positive ventilator-associated pneumonia: retrospective analysis of two double-blind studies comparing linezolid with vancomycin. Intensive Care Med. 2004;30(3):388-394.

102. Stevens DL, Herr D, Lampiris H, et al. Linezolid versus vancomycin for the treatment of methicillin-resistant Staphylococcus aureus infections. Clin Infect Dis. 2002;34(11):1481-1490.

103. Rubinstein E, Cammarata S, Oliphant T, et al. Linezolid (PNU100766) versus vancomycin in the treatment of hospitalized patients with nosocomial pneumonia: a randomized, double-blind, multicenter study. Clin Infect Dis. 2001;32(3):402-412. 
Core Evidence

\section{Publish your work in this journal}

Core Evidence is an international, peer-reviewed open-access journal evaluating the evidence underlying the potential place in therapy of drugs throughout their development lifecycle from preclinical to postlaunch. The focus of each review is to evaluate the case for a new drug or class in outcome terms in specific indications and patient groups.

The manuscript management system is completely online and includes a very quick and fair peer-review system, which is all easy to use. Visit http://www.dovepress.com/testimonials.php to read real quotes from published authors.

Submit your manuscript here: http://www.dovepress.com/core-evidence-journal 